Social and Education

History

Hipatia Press

www.hipatiapress.com

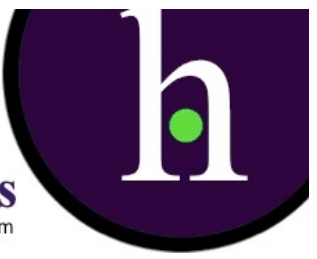

Instructions for authors, subscriptions and further details:

http://hse.hipatiapress.com

\title{
Between Educationalization and Appropriation. Selected Writings on the History of Modern Educational Systems
}

Jon Igelmo Zaldívar ${ }^{1}$

1) Queen's University/Universidad de Deusto

Date of publication: February, 23th 2013

To cite this review: Igelmo, J.(2013). Between Educationalization and Appropriation. Selected Writings on the History of Modern Educational Systems [Review of the book]. Social and Education History, 2(1), 101-104. doi: $10.4471 /$ hse. 2013.05

To link this review: http://dx.doi.org/10.4471/hse.2013.05

\section{PLEASE SCROLL DOWN FOR ARTICLE}

The terms and conditions of use are related to the Open Journal System and to Creative Commons Non-Commercial and Non-Derivative License. 


\section{Reviews (I)}

Depaepe, M. (2012) Between Educationalization and Appropriation. Selected Writings on the History of Modern Educational Systems. Bélgica: Luven University Press. ISBN: 978-90-5867-917-8

Los estudios del profesor Marc Depaepe se presentan en la actualidad como un intento pionero por estudiar la educación y su historia desde una perspectiva acorde a la crítica epistemológica de la historia en el siglo XXI. Sus artículos publicados en los últimos 25 años son una referencia obligada para todos aquellos que desde la historia de la educación abordan investigaciones y reflexiones no sólo sobre el impacto que la expansión de las instituciones educativas ha alcanzado en diferentes contextos sociales, sino también en relación con el significado que las propias instituciones educativas tienen en distintas culturas. Dentro de la comunidad científica de la historia de la educación, son pocos, en verdad, los que discuten en la actualidad la repercusión que los trabajos de Deapepe poseen para el estudio y conocimiento de los procesos de expansión y apropiación del discurso educativo.

El libro titulado Between Educationalization and Appropriation. Selected Writings on the History of Modern Educational Systems, editado en 2012 por Luven University Press, se presenta como una recopilación de los principales textos publicados por Depaepe durante las dos últimas décadas junto con algunos de sus más estrechos colaboradores y colegas, es el caso de Frank Simon, Hilde Lauwers, Geert Thyssem, Paul Smeyers, Frederik Herman, Melanie Surmont, Angelo Van Gorp, Kristof Dams y Raf De Bont. En su mayoría estos artículos han sido publicados en las más destacadas revistas que han liderado las investigaciones en historia de la educación en el contexto

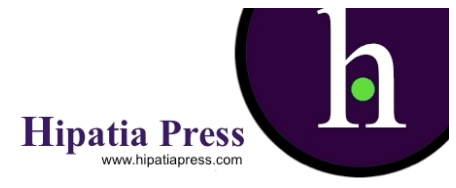


internacional, es el caso de: History of Education Review, History of Education Quarterly, Paedagogica Historica, European Educational Research Journal y Educational Theory.

La división de capítulos que estructura el conjunto de textos que conforman el libro merece ser tenida en cuenta. En buena medida las cinco partes de la publicación bien pueden ser consideradas como los cinco grandes temas que agrupan los textos publicados por Depaepe. El primer capítulo se titula: "Comenzando por el caso de Bélgica; de la escolarización a la educacionalización" (Starting from the Belgian case - from schooling to educationalization) y se centra en el estudio de las condiciones culturales, políticas, económicas y sociales que en un país como Bélgica han ocasionado que se haya consolidado en el tiempo el fenómeno de la educacionalización (del alemán Pädagogisierung). Siendo este un marco teórico de la educación que si bien para Depaepe se puede decir que ha nacido dentro de la apuesta decidida por la escolarización consolidada durante buena parte del siglo XX, se ha posicionado en las últimas décadas como un principio que define la forma en que en Bélgica se piensa el potencial intrínseco de la pedagogía y sus instituciones.

La segunda parte lleva por título "Sobre la educacionalización... de occidente" (About the Educationalization... of the West). En este apartado lo que Depaepe explora es la posibilidad de generalizar sus estudios sobre el fenómeno de la educacionalización en Bélgica al conjunto de la cultura occidental. Esta ampliación del campo de estudio permite al historiador definir con mayor precisión lo que se esconde detrás de este neologismo, que no es otra cosa que la creciente apuesta de las sociedades occidentales modernas por situar a la educación como referencia de primer orden para la solución de los principales problemas referentes a la justicia social, la convivencia cultural y el orden político. La educación, desde esta perspectiva, se convierte en una palabra "paraguas" que resguarda a otros ámbitos de la vida social de la responsabilidad que conlleva su desempeño. En este contexto discursivo la educación lo abarca todo, al tiempo que encierra la respuesta para los males más acuciantes de un tiempo determinado. Es por eso que en última instancia, la educacionalización, conlleva la tendencia manifiesta de impulsar la constante adaptación de las personas al sistema económico y político hegemónico y nunca al contario. 
Los dos siguientes capítulos toman como referencia, por una parte, el rol de las instituciones educativas en los procesos de educacionalización en el contexto de la colonia, es el caso de los estudios históricos en el contexto del Congo Belga, y, por otra, un acercamiento histórico al proceso de apropiación. Sin duda, estos artículos ponen de manifiesto el trabajo de historiador minucioso desarrollado por Depaepe en sus más destacados textos. En su conjunto estas dos líneas de investigación marcan un territorio de posibilidad de conocimiento para quienes en la actualidad desempeñan su labor en el campo de investigación de la historia de la educación. El título de estos dos capítulos son respectivamente: "El contexto colonial - ¿De la educacionalización a la apropiación?" (About the Educationalization... of the West) y "El proceso de apropiación en la teoría y la práctica" (Appropriation Processes in Theory and Praxis).

Finalmente, el último de los capítulos, el quinto, titulado "El autoconcepto de la "nueva historia cultural" de la Educación desmitologizada" (The Self-Concept of a Demythologized 'New Cultural' History of Education), abarca una excelente selección del trabajo historiográfico presentado por Depaepe en las dos últimas décadas. Con seguridad es en este ámbito en el que sus trabajos son una referencia de primer orden a nivel internacional. Su indagación en las posibilidades y limitaciones que la "nueva historia cultural" presenta para los estudios históricos en el campo de la educación poseen una fundamentación teórica y filosófica de gran calado. La reivindicación que recorre estos trabajos es que los historiadores de la educación deben considerarse a sí mismos como historiadores y no como sirvientes o defensores de una determinada práctica pedagógica, teoría de aprendizaje o idea educativa.

Por todo ello, el libro Between Educationalization and Appropriation. Selected Writings on the History of Modern Educational Systems se presenta como una excelente recopilación de artículos que muestran a las claras la dimensión que para la historia y la historiografía de la educación tiene la obra de un autor minucioso, preciso, innovador y profundo como lo es Marc Depaepe. Un historiador que es en la actualidad una de las figuras más reconocidas del campo académico de la historia de la educación y que desde hace años ha desempeñado su 
104 Igelmo-Between Educationalization and Appropriation [Book Review]

labor como profesor en la Universidad Católica de Lovaina (Bélgica) dentro de la Facultad de Psicología y Ciencias de la Educación.

Jon Igelmo Zaldívar, Queen's University/Universidad de Deusto jigelmoza@deusto.es 